\title{
DAS FORMAS DO SAGRADO: 0 ESPAÇO NO KALARI E I NQU I ETAÇÕES SOBRE O FAZER DA CENA
}

RESUMO

Este artigo aborda a questão da construção/transformação do espaço comum em lugar propício para a manifestação do sagrado. Partindo da concepção e da preparação dos espaços na prática do Kalarippayatt, arte marcial indiana; das noções de sagrado proposto por Mircea Eliade e da diferenciação entre espaço e lugar proposta pela geografia das religiões, a autora indaga sobre a possibilidade de olhar para essas formas de elaboração espacial dentro do fazer cênico contemporâneo ocidental.

Palavras-chave:

lugar cênico; formas da cena; cena e sagrado. 


\section{Das formas do sagrado: o espaço no Kalari e inquietações sobre o fazer da cena}

Ana Paula Ibañez - Mestre em Artes da Cena. Doutoranda no Programa de Pós Graduação em Artes da Cena. pauluxka@gmail.com

Marilia Vieira Soares - Professora Doutora. Orientadora de Ana Paula Ibañez. mvbaina@gmail.com

\footnotetext{
${ }^{1}$ Mahashivaratri: 'A grande noite de Siva', neste dia são realizadas oferendas para Siva, com o intuito de que sejam eliminados os percalços do caminho para o autoconhecimento e para que todo o ser fique livre de sofrimento.

${ }^{2}$ Lord Ananta: Ananta é a serpente de 1000 cabeças, sobre a qual repousa Vishnu, flutuando nas águas primordiais, no intervalo dos ciclos cósmicos. O mundo repousa na cabeça de Ananta. A cada final de ciclo cósmico, o mundo é destruído por sua flamejante respiração. ${ }^{3}$ Kalari: Ginásio. Lugar onde tradicionalmente é praticada a arte marcial Kalarippayatt.
}

Era dia 10 de fevereiro de 2010. Véspera de Mahashivaratri ${ }^{1}$. Aterrissava em Thiruvananthapuram, a cidade do Lord Ananta ${ }^{2}$, a cidade da felicidade, no estado de Kerala, sudoeste indiano.

Eram 3 horas da manhã e as ruas estavam inundadas de pessoas asseadas e arrumadas que caminhavam com passos ligeiros em direção aos templos. Uma miscelânea de odores, cores, rostos, vozes, buzinas, mantras e, consequentemente, tempos. Aquela avalanche de informações desconhecidas fez com que todos os meus sentidos ficassem despertos, e de dentro do carro que me conduzia ao hotel, percebi que o encontro com aquela mixórdia produzia em mim um estado de alerta e atenção.

Na proteção do quarto do hotel, distanciei-me por um momento daquela avalanche de informações; um passo atrás, uma respiração profunda antes de saltar definitivamente na Índia. Mergulho em queda livre desde um penhasco em um mar (ou não) de possibilidades.

Às 10h da manhã, meu professor chegou para me levar a seu Kala$r i^{3}$, o Kerala School of Martial Arts (KESMA).

Seu Kalari era também sua casa, e as portas estavam abertas para me receber da mesma forma como haviam recebido os quatro alunos europeus que haviam chegado antes de mim.

O Kalari de meu mestre era na laje. Em princípio e idealmente o Kalari deve ser construído de uma forma determinada com medidas, direção e elementos específicos, para que possa cumprir com total eficiência todas as funções que ali serão desempenhadas: um mesmo espaço será lugar para diferentes práticas - físicas, medicinais e espirituais - que têm como objetivo desenvolver o praticante de forma holística e harmoniosa. 
Segundo Zarrilli (1998), o Kalari tradicional para a prática do vadakkan style - estilo de Kalarippayatt praticado no norte do estado - deve ser construído seguindo elementos extremamente concretos e determinados, com dimensões e proporções específicas. Estes dados são baseados no Vastushastra - antigo livro indiano da arquitetura e construção. Deve ser um lugar fresco, que proteja os praticantes dos possíveis desequilíbrios de seus doshas ${ }^{4}$, da umidade durante o período das chuvas, do calor do verão, dos ventos e das doenças de pele.

Normalmente são construídos abaixo do nível da terra, como buracos retangulares escavados que podem ter $0,5 \mathrm{~m}$ a $2 \mathrm{~m}$ de profundidade. As paredes e o chão são de terra batida, o que faz com que seja mantida uma temperatura constante, propícia para a prática.

As medidas são ajustadas de acordo com a impressão que o $a s a r i^{5}$ tenha da situação. Ele lerá marcas e sinais do lugar escolhido para a construção do Kalari e determinará suas medidas: profundidade, orientação e localização exata, que normalmente é no canto sudeste do terreno.

Além disso, o Kalari contará com um altar formado por sete degraus - puttara- onde os deuses que protegem esta arte se fazem presentes e serão saudados diariamente. Zarrilli (1998, p. 62) nos explica que "o Kalari tradicional indiano é um templo, onde os deuses são venerados, um lugar para a prática de exercícios e armas, e uma clínica, onde tratamentos são administrados"6.

\footnotetext{
${ }^{4}$ Dosha: são os humores que nos constituem segunda a Ayuverda (sistema medicinal de Kerala).

${ }^{5}$ Asari: reconhecido conhecedor da arte da arquitetura que deve ser consultado sempre que uma casa e/ou Kalari forem ser construídos.

${ }^{6}$ No original: The traditional Hindu Kalari is a temple, where the deities are worshipped, a place to practice exercises and weapons, and a clinic where treatment is administered. (ZARRILLI, 1998, p 62).
}

O Kalari tradicional não conta com um teto fechado. A partir do nível do solo, pilares de madeira de aproximadamente 10 metros são fixados para sustentar uma estrutura, também de madeira, onde são colocadas folhas de coqueiro. A ventilação do Kalari é feita desta forma, pela abertura superior.

Já no tekkan style, ou estilo do sul, o Kalari normalmente é construído no mesmo nível que o solo, ou com pouca profundidade. Suas paredes são de pedra ou de folhas de palmeiras, e o telhado, de folhas de palmeira, pode ser construído a partir do final das paredes ou apoiado em pilastras de madeira. Neste estilo, as práticas também podem ser realizadas ao ar livre. Porém, todos os outros elementos seguirão as mesmas regras: a melhor localização é no sudeste do terreno, ainda que em casos específicos o asari possa achar melhor que o mesmo seja construído em outra posição; a entrada será do lado leste do espaço de treino, para receber os raios de sol da manhã; à esquerda do altar serão colocadas fotos dos antepassados do Guru (Gurutrara) e quadros de alguns deuses; acima dos retratos e ao longo da mesma parede oeste, estarão dispostas as armas. E também compreende as funções de templo e clínica, como no vadakkan style.

A seguir, uma imagem do Kalari no Kettan Style e um desenho de Zarrilli sobre a disposição interna do Kalari.

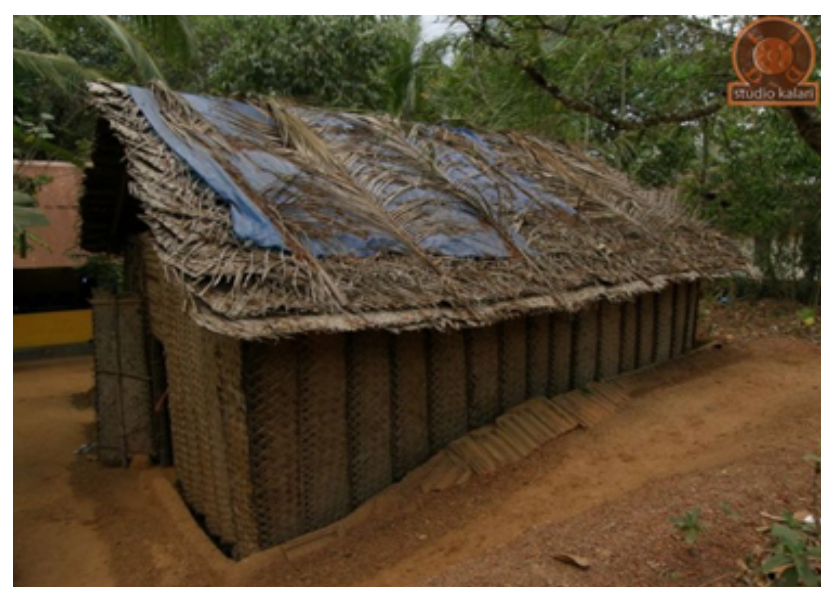

Figura 1 - foto externa de um Kalari do estilo do sul (Tekkan Style). Imagem disponível no site: http://www.studioKalari.art.pl/index.php?option=com_content \&view=article\&id=58\&Itemid=55\&lang=en 

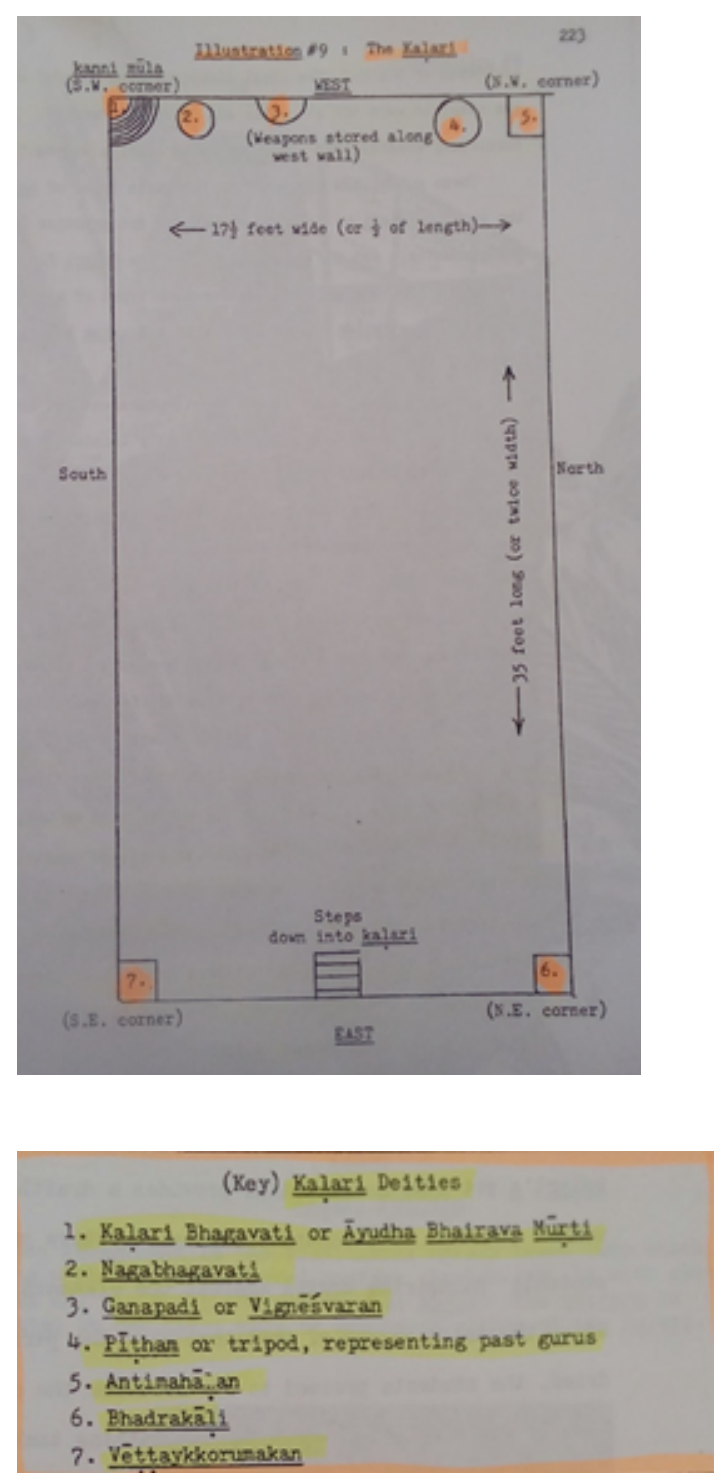

Figura 2 - disposição interna do Kalari e legenda de deidades. ( ZARRILLI, 1978, p. 223 - 224)

Na KESMA pratica-se o Kettan Style. Toda a vida familiar de Master Joy gira em torno das práticas de Kalarippayatt. Durante o período em que recebe em sua casa alunos vindos de tantos outros cantos, toda a estrutura doméstica se volta para que a estadia de seus aprendizes seja a mais agradável possível.

Durante os meses em que estive lá, nossas práticas matutinas começavam às cinco horas da manhã, antes que o grandioso sol de Kerala surgisse no horizonte e tornasse impraticável a nossa estada na laje.
A prática começava com a preparação do lugar. Limpávamos o chão, dispúnhamos as armas no lugar determinado pelo Master.

Nosso Kalari não tinha puttara, nem o chão de terra batida, nem teto de folhas de coqueiros, nem paredes feitas por frescas folhas de palmeiras. Não havia sido construído no canto sudeste do terreno, nem havia seguido as normas do Vastushastra. Não havia deidades, nem retratos. Mas estava direcionado para leste, que segundo Zarrilli (1978) é um dos quesitos mais importante, e recebíamos a energia do sol nascente todas as manhãs.

As armas estavam dispostas no lado oposto da saída do sol, ao lado de onde, segundo as sagradas escrituras da arquitetura, deveria estar o puttara. Elas eram reverenciadas a cada início e a cada finalização de prática.

A transformação do espaço em um 'outro lugar' se consolidava com a presença de Master Joy, sua forma de conduzir nosso mergulho no Kalarippayatt, seu olhar atento a cada detalhe e a cada necessidade individual, seu desejo e consciência de dever ao compartilhar o que sabia, materializando em suas ações uma vasta linhagem de antigos mestres e de muita sabedoria, o gesto firme e ao mesmo tempo acolhedor, concedia um novo caráter à 'laje de todos os dias', e ela se tornava um espaço-tempo outro, permeando-nos de reverência e respeito.

Nas ações reais de limpar e organizar o espaço, na forma como se fazia presente Master Joy em comunhão e diálogo a nossa atenção e desejo de apre(e) nder, se manifestava o sagrado, ainda que fosse, contudo, a mesma laje onde colocávamos a roupa limpa para secar ao sol:

Manifestando o sagrado, um objeto qualquer torna-se outra coisa e, contudo, continua a ser ele mesmo, porque continua a participar do meio cósmico envolvente. Uma pedra sagrada nem por isso é menos uma pedra; aparentemente (para sermos mais exatos, de um ponto de vista profano) nada a distingue de 
todas as demais pedras. Para aqueles a cujos olhos uma pedra se revela sagrada, sua realidade imediata transmuda se numa realidade sobrenatural. (ELIADE, 1992, p. 13)des textes fondateurs? Mais les aviez-vous seulement lus alors?

Todas as manhãs éramos banhados pelo nascer do dia durante nossas práticas, e nos tornávamos cada vez mais conscientes da grandiosidade e da força de tudo o que ali se construía, de tudo o que era transformado e transmutado a partir de determinada presença, de um determinado olhar, de uma certa prática.

A sequência de rituais e a evocação do sagrado realizados pelos praticantes de Kalarippayatt são diárias, independem do estilo praticado e afetam diretamente o cotidiano.

Desde o levantar-se muito cedo, assear-se, ir ao templo em jejum, render homenagem à(s) deida$\mathrm{de}(\mathrm{s}) \mathrm{da}(\mathrm{s})$ qual(is) é devoto. Voltar para casa, tomar um tchai, preparar o espaço, preparar o corpo com óleo para a prática, adentrar o espaço das práticas sempre com o pé direito- tocando sempre o chão com a ponta dos dedos e levando estes à frente e ao peito em sinal de reverência- tocar os pés do Guru, dirigir-se ao puttara, saudar as deidades protetoras do Kalari, fazer o Guruvandana ${ }^{7}$, homenageando todos os Gurus que existiram e demonstrando respeito pela tradição que representam e, somente então, iniciar o treinamento propriamente dito. Realizar,

\footnotetext{
${ }^{7}$ Guruvandana: sequência de abertura e encerramento onde são saudados os Deuses e toda a linhagem de Gurus do Kalari.

${ }^{8}$ Meyppayatt: sequências de exerc' cicios que preparam o corpo para a correta execução dos movimentos que compões a luta.

${ }^{9}$ Assanas:

10 Ayurvédico: refere-se à medicina Ayurvédica, "a palavra Ayurveda é proveniente do sânscrito e possui duas partes: Veda que é traduzido como conhecimento, ciência ou sabedoria e Ayus que significa vida. Neste contexto Ayurveda é o conhecimento, a ciência ou sabedoria que propõe uma vida saudável em harmonia com as leis da natureza com o objetivo de alcançarmos a felicidade. Nesta filosofia indiana a saúde é um estado de completude... O Ayurveda possui 2 objetivos principais: preservar e promover a saúde das pessoas saudáveis e curar as doenças dos pacientes. " (in: http://www.ayurveda.org.br/pagina/78/o-que-e -ayurveda.html)
}

durante o desenrolar da prática, diferentes outros pequenos, mas tão importantes quanto os primeiros, ritos: manter silêncio, tocar as armas e levar a mão à frente e ao peito em sinal de respeito antes de iniciar o treino com elas, reverenciar sempre o oponente, olhar nos olhos. Ao finalizar a jornada, volta a realizar o gurvandana, agora em agradecimento pelo treinamento realizado, dirigir-se uma outra vez ao puttara, tocar com as pontas dos dedos a base do altar e levar a mão à frente e ao coração, tocar novamente os pés do Guru, e ao sair do espaço, sem nunca dar as costas a ele, tocar o chão em agradecimento a Bhumi Devi, a mãe terra, por permitir que o aprendizado ocorra sobre ela.

Através destas ações, os espaços se transformavam em lugares: "Os lugares simbólicos são lugares criados pela ocupação humana dos espaços e pelo uso de símbolos para transformar aquele espaço em lugar" (NORTON apud ROSENDHAL, 2008, p. 6).

Ao referir-me a espaços, no plural, falo dos espaços internos que também são transformados em lugares a partir do contato e da incidência direta de uma determinada ação externa. Ao agir sobre e sofrer a ação transformativa do espaço, os corpos físico e sutil do praticante são também passíveis de transmutação, podendo tomar para si outras formas e ampliar suas percepções e consciência sobre o que é real. Neste sentido, uma vez mais nos aproximamos de Eliade (1992), no que tange o sagrado como a revelação por excelência da realidade.

Éramos europeus, indianos, mais jovens, mais velhos, hindus, muçulmanos, católicos, ateus, movidos por distintas inquietações e buscando no Kalarippyatt possíveis caminhos. Porém, sem exceções, todos deveríamos abrir nossos corpos e mentes de acordo com nossas capacidades e flexibilidades individuais, para aquilo que nos era oferecido.

Após esta prática matutina, que normalmente consistia de meyppayatt ${ }^{8}$, assanas ${ }^{9}$ e alongamento, nos banhávamos em água fria, untávamos nossos corpos com Mureveena - um óleo ayurvédico ${ }^{10}$ que deve ser aplicado após a prática - e sentávamos para tomar o café da manhã. Agora era o momento de 
que nosso corpo experimentasse um universo de sabores e cheiros. A comida, caprichosa e meticulosamente preparada por Molly, servia para alimentar nossos corpos de forma que pudéssemos alimentar nossas expectativas com o Kalarippayatt.

Durante a tarde descansávamos. Momentos (necessários) para os tempos pessoais. Pausas para respirar e perceber as transformações que, sutil e continuamente, iam tomando forma. Revelações de lugares escondidos, a necessidade de aniquilar necessidades.

Às seis e meia da tarde retomávamos as práticas até às dez da noite. Para tal, uma vez mais o espaço deveria ser preparado, transmutado uma vez mais, deixando de ser simples laje para dar espaço a um lugar outro. Uma vez mais varríamos o chão, dispúnhamos as armas. E agora instalávamos também a luz: uma lâmpada era acendida a partir de fios que eram puxados da sala. $\mathrm{O}$ trabalho desenvolvido à noite era sempre a partir da execução dos cuvadukals ${ }^{11}$, a prática com as armas de madeira (cheru vathi e nethu vathi) e metal, ati data (luta sem armas, especificidade deste estilo), locks and releases (bloqueios e desbloqueios do adversário). A penumbra nos obrigava a ter mais atenção, a olhar mais detalhada e cuidadosamente tudo o que ali acontecia.

Adentrar nas práticas de Kalarippayatt a partir da perspectiva de que estas acontecem em espaços de hierofânia, é transformar a prática em si e por ela ser transformada, uma vez que, ainda que não saiba exatamente o porquê ou o para quê de uma série de ações, estas ações conduzem um determinado tempo/espaço/forma de realização e atravessam inevitavelmente quem as realiza.

A prática do Kalarippayatt, com as necessidades de transformação dos espaços que estão implicados, acaba por concretizar em ações tanto a perspectiva proposta pela Geografia das Religiões, onde o espaço

\footnotetext{
${ }^{11}$ Cuvadukals : sequências onde são treinados com precisão os golpes que estarão presente tanto durante os confrontos a mão livre como nos que se utiliza armas.
}

se transforma em lugar de hierofânia a partir da intervenção do homem e da inserção de símbolos com uma finalidade específica, como também dialoga com a definição de sagrado proposta por Eliade, e passa a configurar um convite para adentrar em um espaço liminal no qual as realidades podem ser dilatadas e transformadas.

Há, portanto, um espaço sagrado, e por consequência "forte", significativo, e há outros espaços não sagrados, e por consequência sem estrutura nem consistência, em suma, amorfos [...] essa não-homogeneidade espacial traduz-se pela experiência de uma oposição entre o espaço sagrado - o único que é real, que existe realmente - e todo o resto, a extensão informe, que o cerca. [...]Quando o sagrado se manifesta por uma hierofânia qualquer, não só há rotura na homogeneidade do espaço, como também revelação de uma realidade absoluta, que se opõe à não realidade da imensa extensão envolvente. [...] O limiar que separa os dois espaços indica ao mesmo tempo a distância entre os dois modos de ser, profano e religioso. O limiar é ao mesmo tempo o limite, a baliza, a fronteira que distinguem e opõem dois mundos - e o lugar paradoxal onde esses dois mundos se comunicam, onde se pode efetuar a passagem do mundo profano para o mundo sagrado [...] O limiar, a porta, mostra de uma maneira imediata e concreta a solução de continuidade do espaço; daí a sua grande importância [...] porque se trata de um símbolo e, ao mesmo tempo, de um veículo de passagem. (ELIADE, 1992, p.17 - 19).

Neste sentido, nos aproximamos exatamente do lugar onde o processo criativo pode ocorrer: na liminariedade, nos espaços entre uma realidade homogeinizada e amorfa e uma outra desvelada em toda a sua potencialidade. Espaço que nos recoloca em um lugar de trânsito, nas bordas de quem somos. 
Cabe esclarecer que para que esta percepção ocorra, para que este lugar possa ser experienciado é necessário o cultivo de um olhar diferenciado, de um desejo de evocação do sagrado, de uma reconstrução e materialização dos elementos que tornam possíveis a hierofânia.

Não basta simplesmente organizar o espaço de uma forma determinada, com elementos determinados; esta é apenas uma das ações, ainda que de suma importância e condutora de todo o resto, para que ocorra a transmutação de espaço em lugar.

Não basta simplesmente limpar a laje ou colocar as armas na parede, no lugar determinado; essa ação por si só não será transformadora do lugar, porém é necessária para que o resto se instaure. Neste sentido, a reorganização do espaço assume a função de veículo para uma transformação. Sem a presença de Master Joy e representação de toda uma linhagem de antigos gurus em suas ações e ensinamentos, bem como sem o desejo dos presentes em receber o que ali é exposto, não haveria hierofânia. Da mesma forma, sem a preparação do espaço para recebe-lo, também não haveria.

Eliade (1992, p. 19) nos esclarece que "o ritual pelo qual o homem constrói um espaço sagrado é eficiente à medida que ele reproduz a obra dos deuses ", ou seja, é necessária a evocação, é necessário o rito e a concretização da realidade em toda a sua potencialidade para que aconteça a manifestação do sagrado.

Transportemos, agora, esse raciocínio para o processo de construção de cena nos dias de hoje, em nosso contexto ocidental.

De que forma há realmente uma preocupação de transformar os espaços em lugares, entendendo ambos como nos expõe a Geografia das Religiões, no processo cênico atual? Está o artista cênico atento a esta possibilidade? De que forma são escolhidos e dispostos os elementos dentro de uma cena? De que forma é concebido o espaço onde a cena se desenvolverá? De que forma cultivamos o olhar para esses elementos?
Não poderíamos nos alimentar, talvez, da meticulosidade e do cuidado presente na preparação do espaço para a prática do Kalarippayatt, e que traz em si um objetivo maior, um cultivo, uma necessidade de manutenção e de reencontro com sutilidades, e que se torna veículo para que a realidade seja dilata$\mathrm{da}$, transformada e, por que não, inclusive, re-compreendida?

Se nos aproximamos ao processo de criação cênica como um rito para que que algo forte e potente possa ser instaurado, como um ponto fixo que possibilita a orientação dentro da caótica homogeneidade cotidiana (ELIADE, 1992), e empreendermos este caminho a partir ideia de artes da cena como espaços para a hierofânia, como pontos fixos que promovem as transformações, somos imediatamente convidados a sermos, nós mesmos, espaços também de hierofânia, cultivando em nossos corpos, ações e presenças a possibilidade de transmutação de realidades internas.

Neste sentido, podemos também nos aproximar de Daniel P. Reis, uma vez que para criarmos e nos tornarmos espaços de hierofânia, é necessária a prática diária, é necessária a construção e o cultivo de uma forma de agir, e que esta prática seja, também em si, transformadora:

O treinamento, ou a preparação, tornase assim cultivo. A ação artística emerge dessa experiência diária de cultivo de um pensamento-ação mais liberto porque menos condicionado pelos padrões de percepção. Treinar deixa de se definir como um meio para chegar a um fim, sendo entendido enquanto ação que se insere no processo de desautomatização das percepções e ações que compreendem todos os aspectos da experiência do indivíduo. (REIS, 2015, p 128). 
Ao olharmos para o fazer cênico desde este prisma, onde a construção, elaboração, materialização do espaço é um veículo para que o sagrado possa ser manifesto dentro do fazer artístico, possibilitamos que o encontro promovido pelo teatro seja também uma possível via transformadora, não somente para os executantes das artes, mas como porta aberta também para os espectadores.

Cultivar o espaço cênico, dentro desta perspectiva, é também uma via para o cultivo de si.

Todo espaço sagrado implica uma hierofânia, uma irrupção do sagrado que tem como resultado destacar um território do meio cósmico que o envolve e o torna qualitativamente diferente. (ELIADE, 1992, p. 20) 


\title{
REFERÊNCIAS BIBLIOGRÁFICAS
}

REIS, D.P. Corpo, Técnica e Vazio: a cena expandida contemporânea e os diálogos interculturais com o Oriente, o treinamento do ator no contexto da prática de mindfulness. In: ABRACE: arte, corpo e pesquisa: experiência expandida, Costas, AMR [et al] [org]. Belo Horizonte: Abrace gráfica e Ed O Lutador, 2015.

ELIADE, M. O Sagrado e o Profano. Trad. Rogério Fernandes.1.ed. .São Paulo: Livraria Martins Fontes Ltda, 1992.

ROSENDHAL, Z. A dimensão do lugar sagrado. In: Geo-working papers. Nucleo de Investigação em Geografia e Planejamento. Universidade do Minho: Guimarães, 2008. Disponível em: http://www.lasics.uminho.pt/ojs/index.php/geoworkingp/article/ view/444. Último acesso em 28/05/2017.

ZARRILLI, P.B. Kalarippayatt and the Performing Artist. East and West, Past, Present, Future. $629 \mathrm{f}$. Tese (doutorado). Minnesota: Faculty of the Graduate School, University os Minnesota, 1978.

Galeria de Imagens. Disponível em: http://www.studioKalari.art.pl (último acesso em $15 / 05 / 2017)$

\begin{abstract}
This paper looks for the possibility of construction/ transformation of the common space into a place where the sacred could be manifested. Approaching to the subject from the conception and the activity done in readiness for Kalarippayatt practices; from Mircea Eliade's concept of sacred and the concept of space and place given by Geografy of Religions, the author looks towards the creative process incontemporany scene arts.
\end{abstract}

\section{KEYWORDS}

scenic place; scene's form; scene and sacred. 